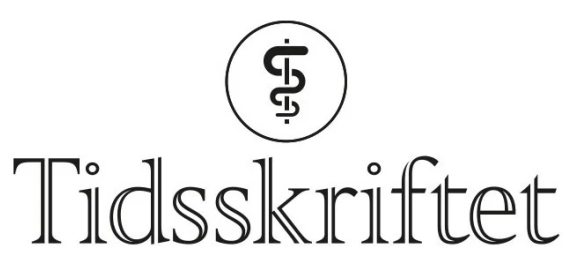

DEN NORSKE LEGEFORENING

\title{
Leger ved samlebåndet
}

ESSAY

ANDREAS NYDAL

andnyd@gmail.com

Andreas Nydal er lege i spesialisering i psykiatri ved Lovisenberg og deltidsansatt ved Senter for fruktbarhet og helse ved Folkehelseinstituttet.

Forfatter har fylt ut ICMJE-skjemaet og oppgir ingen interessekonflikter.

\section{Legers utmattelse handler om noe mer enn mangel på tid og} ressurser. Det handler om måten vi jobber på.

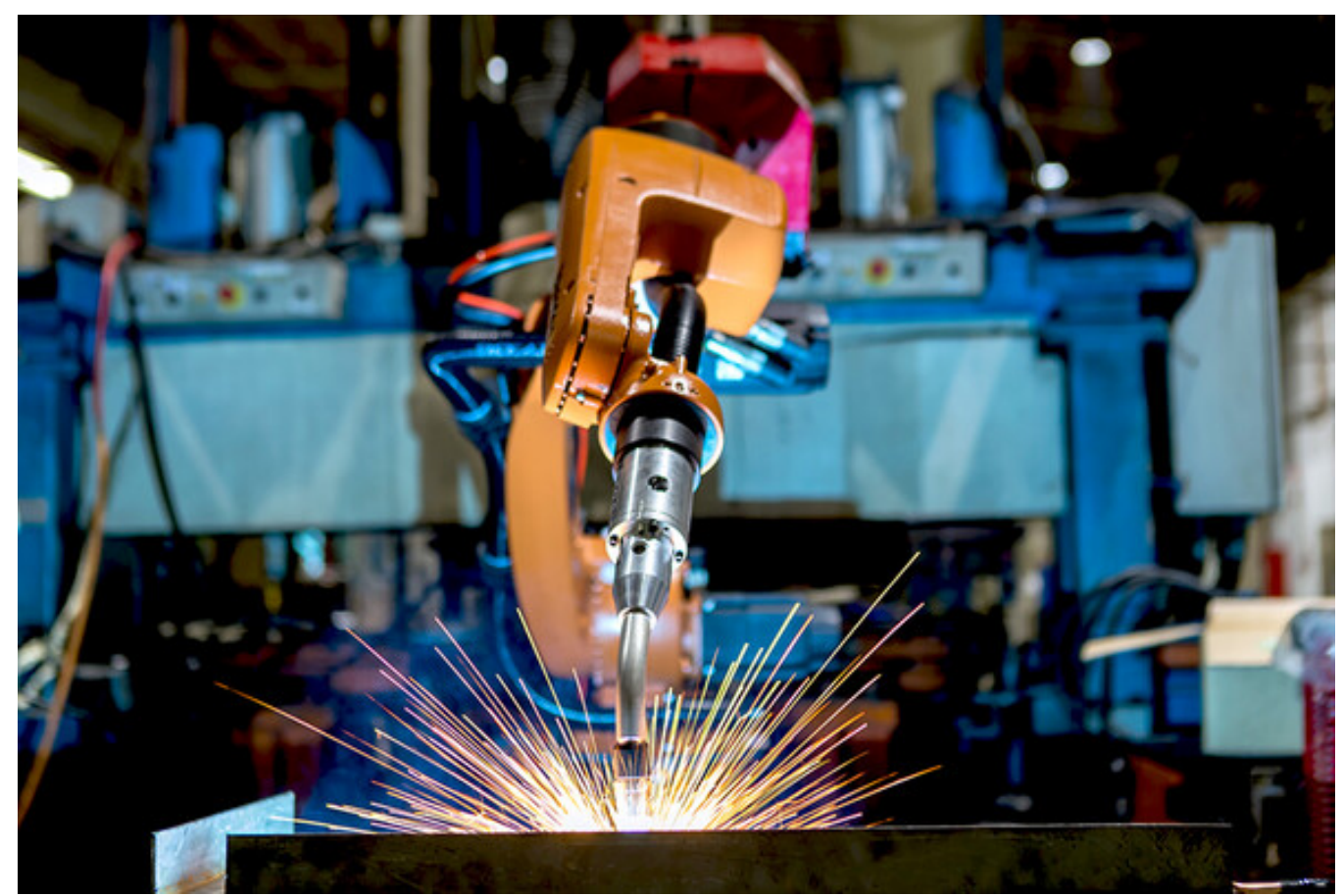

Illustrasjon: Thossaphol / iStock

Hva har skjedd med legeyrket? På sykehusene har antallet leger per pasient økt de siste tiårene (1). Likevel virker mange leger utmattede. Fastleger forteller om stor arbeidsbelastning og mange slutter (므). Så mange som en av tre nyutdannede leger i Sverige angir at de sannsynligvis vil slutte å arbeide som leger i løpet av de neste fem årene på grunn av høy arbeidsbelastning, stress og dårlig arbeidsmiljø (3). 
Det ropes etter mer penger og mer tid $(\underline{2}, 4$.), men hva om problemet stikker dypere? At det handler om en såkalt teknologisering av arbeidet, en uheldig fragmentering av legevirksomheten som går på bekostning av meningsfylden? Vi skal til Henry Fords bilfabrikk i år 1913 for å illustrere poenget.

\section{Henry Fords bilfabrikk}

I 1913 ble Ford den første bilprodusenten til å ta i bruk samlebåndet $(5, \underline{6})$. Arbeiderne hans hadde tidligere lagd biler. Nå lagde de tusenvis av dørhåndtak og gikk fra å være bilbyggere til å bli mutterskruere. «The man who places the part doesn't fasten it, the man who puts in a bolt doesn't put on the nut, and the man who puts on the nut, doesn't tighten it», proklamerte Ford stolt til besøkende ingeniører. Ikke overraskende mislikte arbeiderne dette. En bølge av misnøye skylte over fabrikken. Bare hør denne arbeiderens beskrivelse av sin tid ved bilfabrikken: «et bittert minne, en form for helvete på jord som forvandlet mennesker til roboter» (egen oversettelse) (5).

\section{«En effektiv produksjonsprosess hjalp lite når folk hatet jobben»}

Folk sluttet i hopetall. Ford måtte ansette mer enn 52 ooo menn i 1913 bare for å opprettholde en arbeidsstyrke på 14000 (7.). En effektiv produksjonsprosess hjalp lite når folk hatet jobben. Ford innså dette og kom opp med en genial plan - økt lønn. Han gjorde ikke dette for å være snill, men for å stabilisere arbeidsstyrken, uttalte Bob Kreipke, historiker ved Ford Motor Company i et radiointervju (5) - «Og det gjorde det sannelig», la han til.

For en kald januarmorgen i 1914 stilte tusenvis av folk seg i kø utenfor Ford-fabrikken i Detroit. Henry Ford hadde tilbudt dem over dobbel dagslønn og attpåtil kortere arbeidsdag. De skulle tjene 5 dollar dagen for 8 timers arbeid, istedenfor 2,34 dollar for 9 timers arbeid. På papiret en fantastisk avtale, men det stod noe i liten skrift. En måtte være gift, og om ikke, i det minste ha planer om ekteskap. Man måtte føre en ryddig husholdning, ha en velstelt hage, ikke drive med hasardspill, begrense røyking og drikking, snakke engelsk (eller vise til planer om å lære det) og ikke minst ha hjemmeværende kone $(\underline{6}, \underline{8})$. Kort sagt, leve slik Ford mente man burde leve (7.). Det kom til og med inspektører fra Fords sosialavdeling på hjemmevisitt for å forsikre seg om at alt stod vel til. Over hundre år senere har vi sett lignende tendenser under pandemien, når arbeidsgivere i USA har investert i programvare som har til hensikt å overvåke arbeidstakerne på hjemmekontor $(9, \underline{10})$.

\section{Enorm suksess}

Fords lønnsøkning ble en enorm suksess. I november 1914 var den årlige utskiftningen av arbeidsstyrken på 54 \%, til forskjell fra 370 \% året før $(\underline{6}, \underline{11})$. Ford trengte ikke spesielt dyktige arbeidere, bare folk som var villig til å gjøre de samme repetitive oppgavene dag ut og dag inn. Og nå lagde Ford over halvparten av landets biler med bare en brøkdel av arbeidsstyrken til de andre bilprodusentene.

Arbeiderne profitterte på kortere arbeidstider, høyere lønn og fallende konsumpriser. Samtidig begynte de å bekymre seg over frihetstap, endeløst repetitivt arbeid og «arbeid som tok livet av sjelen» (5). Misnøyen økte i løpet av 1920-årene, og snart kom nye krav om lønnsøkning, som fikk langt mindre uttelling enn det arbeiderne hadde opplevd i 1913. Og samlebåndsarbeidet, som var som skapt for å overtas av maskiner, ble naturligvis det. 
Vedrører noe av dette vår erfaring av å være leger i 2021? Fords samlebånd er et eksempel på teknologisering av arbeid og et skille mellom arbeidet og arbeidets mål. Mellom thinking and doing, som professor D. C. Schindler foreslår i en artikkel om teknologisering av arbeid (므). En kan se for seg helsebyråkraten og fastlegen. For å sette det litt på spissen: Den ene har bare tid til å tenke, den andre har bare tid til å gjøre. Det er flott at noen holder oversikten og ser det store bildet. Samtidig vokser avstanden mellom den som planlegger og den som utfører oppgavene. Pakkeforløp, skjemaer og nasjonale retningslinjer kan oppleves som en virkelighetsfjern fragmentering av arbeidet. Sykehuslegen og fastlegen skal sjonglere alle disse fragmentene, og pasienten som befinner seg et eller annet sted bak papirbunken, blir fjernere og fjernere. Klinikere ved to norske sykehus setter fingeren på dette i en nylig publisert studie (13). De beskriver en opplevelse av at sjefene er mest opptatt av budsjett og behandlingskvantitet, mens samtalen om pasientenes behandlingskvalitet får gradvis mindre rom. Dette skaper fremmedgjøring og frustrasjon.

\section{Legers utmattelse}

Hva skyldes misnøyen blant leger? Jeg tror svaret har å gjøre med at leger mistrives ved samlebåndet fordi legevirksomhet mistrives der.

I en kvalitativ studie fra 2016 kom det frem at noen av de intervjuede overlegene opplevde det å være lege mer som en «livsstil», mens leger i spesialisering i større grad så på det som en «jobb» (14). Legenes totale arbeidstid har endret seg lite de siste tiårene, men tiden brukt til direkte pasientarbeid er redusert (11). Det var kanskje mer fristende å gjøre legeyrket til en livsstil før fordi man hadde mer tid til pasientmøter. Å være bilbygger er en livsstil, å være samlebåndsoperatør er ikke det.

«Foretaksmodellen bidrar slik jeg ser det til å gjøre helsepersonell til samlebåndsoperatører og pasienten til en maskin med ødelagte deler»

Mellom 50-70 \% av legene i en norsk undersøkelse fortalte at de følte ubehag knyttet til konflikten mellom tiden de ønsket å bruke på pasientbehandling og tidsrammen (15). Slikt kan bli utmattende.

En annen, men beslektet utmattelse tror jeg skyldes avmektigheten av å stå ved samlebåndet. At faget blir ofret på produktivitetens alter, akkurat som for Fords bilbyggere. Jeg tror denne utmattelsen er den mest betydelige, fordi den fratar oss noe viktigere enn kreftene våre. «Henry [Ford] har redusert livets kompleksitet til et bestemt antall vridninger, dreininger og vendinger», sa en arbeider ved Fords fabrikk (egen oversettelse) (므). Kanskje det er noe i oss som roper i protest mot denne reduksjonen av livets (og helsens) kompleksitet. Å stå ved samlebåndet og prøve å skru og vri på pasientens deler gir rett og slett ikke mening. At pasienten ruller videre, egentlig uten at du har fått gjort alt du kan, og du ikke har tid til å reflektere over det før neste pasient ruller inn, er i det lange løp ødeleggende for arbeidsgleden.

\section{Pasienten som maskin med ødelagte deler}

Har vi delt inn pasienten i kunstig mange deler? I medisinen må naturen inndeles for å kunne gå vitenskapelig til verks, erkjente Sokrates (므) og ga med det vårt reduksjonistiske menneskesyn en håndsrekning. Men han viste også til Hippokrates' ord om at kunnskap 
om sjelen eller kroppen ikke er mulig uten å kjenne det heles natur. En må ha helheten for øye, selv når en arbeider med delene. At en ikke kan praktisere medisin uten å kjenne til hva helse er, er en annen tolkning av Sokrates (프).

Foretaksmodellen bidrar slik jeg ser det til å gjøre helsepersonell til samlebåndsoperatører og pasienten til en maskin med ødelagte deler. Effektivisering og oppdeling av helseomsorgen gjør det vanskeligere å se hele pasienten.

Kan vår påtvungne samlebåndsmentalitet ha medført endringer hos pasientene? Mitt inntrykk er at vi er bedre til å behandle benbrudd og hjerteinfarkt enn depresjon og uforklarlige magesmerter. Kanskje det er derfor pasienten ønsker å oppfattes som en maskin med ødelagte deler? Den utmattede ønsker å lide av en kurabel virusinfeksjon. Personen med kompleks smerteproblematikk skulle gjerne vist frem et røntgenbilde av en brukken arm. Den deprimerte vil gjerne lide av en kjemisk ubalanse i hjernen. Hvorfor? Fordi vi har bygget et helsevesen som er bedre til å reparere enkeltdeler i kroppen enn å forholde seg til sykdom som et komplekst problem.

\section{Ford eller Toyota?}

Kan det lages biler på andre måter enn ved samlebåndet? Professor i etikk Alasdair MacIntyre skriver at noe som kjennetegner moderne foretak, er myopi (17.). Altså nærsynthet, kortsiktighet og manglende evne til å se det store bildet. På et tidspunkt forlot japanske bilprodusenter samlebåndet og gikk tilbake til arbeid i team preget av ansvar og formålstenkning, påpeker MacIntyre (표). Hos Toyota holder de standardiserte arbeidsplaner til et minimum, noe som tillater fleksibilitet uten at tidsfrister misligholdes (19). Og dersom folk må bruke standardiserte prosesser, skal de kjenne deres formål. Vi vet ikke om arbeiderne er mer fornøyde enn andre, men en nyere Harvard-analyse mener i hvert fall at Toyota ikke ser de ansatte som et par hender, men som arbeidere som akkumulerer chie. Chie er et japansk begrep som oversettes til the wisdom of experience, altså

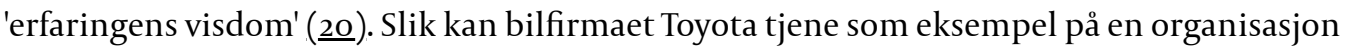
som har ført sammen tenkning og gjøren, de har avteknologisert arbeidet.

\section{«Fastlegekrisen og unge legers utmattelse stikker dypere enn tid og penger. Det handler om arbeidets art»}

Hva med å avteknologisere helsevesenet? Det er en stor utfordring, men kanskje vi kan begynne med å sette sammen noen av delene igjen, både helsevesenets og pasientens. Pasienten er én, og sykdommer oppstår i en kontekst. Et slags kompromiss mellom en ny tenkning og samlebåndet kunne være jevnlige sjekkpunkter hvor vi setter søkelys på helheten. Hvordan ser pasienten ut bak alle kodene, papirene og prosedyrene? Hva trenger de ansatte for å oppleve jobben som meningsfull? Hva er pasientenes største utfordring og behov? Hva er egentlig poenget med pakkeforløp? Kan noen forklare det til oss på en måte som gjør at vi får dyp forståelse for alle leddene, som hos Toyota, samt eierskap til formålet?

\section{Hva kan vi lære av Ford og Sokrates?}

Å stå ved samlebåndet er utmattende på flere måter. Hvis vi ikke har noen del i helheten, blir vi som roboter. Hvis vi har del i helheten, kan vi lettere stå ved samlebåndet i perioder, fordi det gir mening i lys av noe større.

Fastlegekrisen og unge legers utmattelse stikker dypere enn tid og penger. Det handler om arbeidets art. Vi bør strebe etter å utøve legeyrket slik Sokrates ville ønsket det. Sagt enklere: La oss prøve å være mindre lik Ford og mer som Toyota. 


\section{LITTERATUR}

1. Rosta J, Aasland OG. Legers arbeidstid og tid til pasientarbeid i perioden 1994-2014. Tidsskr Nor Legeforen 2016; 136: 1355-9. [PubMed][CrossRef]

2. Kalveland J. Fikk 1,6 milliarder - vil ha 4,8. Dagens Medisin 25.2.2021. https://www.dagensmedisin.no/artikler/2021/02/25/fikk-16-milliarder--vil-ha-48/ Lest 25.9.2021.

3. Petterson J, Börjesson J. I väntan på AT, en samhällsekonomisk studie. Stockholm: Sveriges Läkarförbund, 2019. https://slf.se/sylf/app/uploads/2019/o7/i-vantan-pa-at.pdf Lest 25.9.2021.

4. Trønderopprøret. Fastlegeordning 2.o. https://www.flo20.no/2018 Lest 25.9.2021.

5. Nye DE. America's assembly line. Boston: MIT Press, 2013.

6. Cwiek S. The middle class took off 100 years ago ... Thanks to Henry Ford? NPR 27.1.2014. 2014 https://www.npr.org/2014/01/27/267145552/the-middle-class-took-off-10o-years-ago-thanks-to-henryford? $\mathrm{t}=1633521211971$ Lest 15.6.2021.

7. Firsht E. "Assembly line americanization" Henry Ford's progressive politics. Michigan Journal of History 2012. https://michiganjournalhistory.files.wordpress.com/2014/o2/fall-12-firsht.pdf Lest 15.6.2021.

8. Worstall T. The story of Henry Ford's $\$ 5$ a day wages: It's not what you think. Forbes 4.3.2012. https://www.forbes.com/sites/timworstall/2012/03/o4/the-story-of-henry-fords-5-a-day-wages-its-notwhat-you-think/?sh=518gf699766d. Lest 15.6.2021.

9. Golden J, Chemi E. Worker monitoring tools see surging growth as companies adjust to stay-athome orders. CNBC 13.5.2020. https://www.cnbc.com/2020/05/13/employee-monitoring-tools-seeuptick-as-more-people-work-from-home.html Lest 9.6.2021.

10. Hertz N. Ensomhetens Århundre. Oslo: Res Publica, 2020:182.

11. Anderson M. Ford's five-dollar day. The Henry Ford Blog.

https://www.thehenryford.org/explore/blog/fords-five-dollar-day/ Lest 5.6.2021.

12. Schindler DC. Redeeming work: On techne as an encounter between God, man and the world. I: Lopez A, red. Enlightening the mystery of man: Gaudium et spes fifty years later. Washington, DC: Humanum Academic Press, 2018: 256-74.

13. Baathe F, Rosta J, Bringedal B et al. How do doctors experience the interactions among professional fulfilment, organisational factors and quality of patient care? A qualitative study in a Norwegian hospital. BMJ Open 2019; 9: e026971. [PubMed][CrossRef]

14. Hertzberg TK, Skirbekk H, Tyssen R et al. Den gode legen - sterk og utholdende. Tidsskr Nor Legeforen 2016; 136: 1631-4. [PubMed][CrossRef]

15. Førde R, Aasland OG. Moral distress and professional freedom of speech among doctors. Tidsskr Nor Lægeforen 2013; 133: 1310-4. [PubMed]

16. Platon. Faidros (Elskoven og sjelen); Ion. Oversatt av Egil A. Wyller. Oslo: Aschehoug, 1981:164.

17. MacIntyre A. Why are the problems of business ethics insoluble. I: Baumrin B, Friedman B, red. Moral responsibility and the professions. New York, NY: Haven Publishing, 1982.

18. Macintyre A. Ethics in the conflicts of modernity. Cambridge: Cambridge University Press, 2016.

19. Sobek DK, Liker J, Ward AC. Another look at how Toyota integrates product development. Harvard Business Review 1998. https://hbr.org/1998/o7/another-look-at-how-toyota-integrates-productdevelopment Lest 6.10.2021.

20. Takeuchi H. The contradictions that drive Toyota's success. Harvard Business Review 2008. https://hbr.org/2008/06/the-contradictions-that-drive-toyotas-success Lest 6.10.2021.

Publisert: 13. desember 2021. Tidsskr Nor Legeforen. DOI: 10.4045/tidsskr.21.0325

(C) Tidsskrift for Den norske legeforening 2023. Lastet ned fra tidsskriftet.no 26. april 2023. 